\title{
The Prevalence of Gingival Recession in the Egyptian Population
}

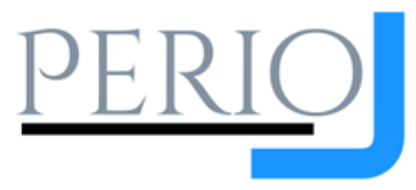

\author{
Marwa Hegab, ${ }^{A}$ Marwa Alnawawy ${ }^{A}$ \\ A Assistant Professor, Department of Periodontology, Faculty \\ of Oral and Dental Medicine, Cairo University, Cairo, Egypt.
}

Accepted for publication: January 17, 2020

\begin{abstract}
Background: Gingival recession (GR) is a challenging condition especially with the increasing esthetic demand of patients today. Hence, there is a need to assess the prevalence of GR and to investigate possible associations with this condition. Methods: A cross-sectional observational study design was used where a sample of 500 patients, within the age range of 18-60 years, was drawn from the Faculty of Oral and Dental Medicine at Cairo University. The collected data included demographic and periodontal variables, and the significance level was set at $P \leq 0.05$. Statistical analysis was performed via IBM ${ }^{\circledR}$ SPSS ${ }^{\circledR}$ Statistics Version 20 for Windows using the Chi-square and Fisher exact test. Results: The overall prevalence of GR was $69.4 \%$. Statistical analysis indicated a significant association between gender and GR (significant male predilection, $\mathrm{P} \leq 0.05$ ), and between $\mathrm{GR}$ and plaque biofilm due to periodontitis with $90.8 \%$ of recession cases having periodontitis. A significant association was also found between the cause and distribution of GR, where mandibular incisors showed the highest prevalence of GR. Conclusion: Gingival recession is a highly prevalent condition among Egyptians, with periodontitis being the fundamental cause. Frenal pull is the most prominent local factor in inducing GR in the Egyptian population. This information can be applied by educating the population and initiating new preventive programs and awareness campaigns.
\end{abstract}

Keywords: Gingival recession; prevalence; classification

\section{Introduction}

One of the fundamental strategies of disease control and prevention is to develop efficient surveillance systems to face current and future challenges. Periodontal disease surveillance has always been difficult to implement due to the need for clinical examination and many resources. Surveillance is essential to describe the burden, identify people at high risk, develop new strategies and preventive and intervention programs, and evaluate their impact on controlling the disease. ${ }^{1}$

Smile esthetics is currently a major concern for many, as it impacts physical attractiveness, self-image, and consequently self-esteem. Many factors play a role in the esthetics of a smile including the facial midline and smile line, tooth color, size, shape, and position, and pink esthetics which is affected by the lip framework in terms of gingival margin position, the color and texture of the gingiva, scarring, gingival recession (GR), and the amount of gingiva displayed by the smile. ${ }^{2}$

Although GR is not a distinct disease entity, several aspects make it clinically significant as it can be disturbing for patients. This is mainly due to its esthetic impact, being one of the most common mucogingival problems that create an esthetic problem for many patients, and also because it can result in psychological and functional problems as a consequence of the exposure of the root surface to the oral environment. ${ }^{3,4}$

Gingival recession is defined as the apical shift of the gingival margin beyond the cemento-enamel junction (CEJ). ${ }^{5}$ It is always associated with attachment loss and root surface exposure to the oral environment. Gingival recession occurs frequently in adults, has a tendency to increase with age, and occurs in populations with both high and low standards of oral hygiene. ${ }^{2}$

Several factors are implicated in the etiology of GR. Poor oral hygiene 
contributes to plaque accumulation and initiation of periodontal disease which may cause recession. ${ }^{6}$ Among the risk factors that have been suggested are a thin periodontal biotype, lack of attached gingiva, and a thin alveolar bony plate as a consequence of abnormal tooth position in the dental arch. ${ }^{2}$ On the other hand, patients with meticulous oral hygiene using improper or aggressive brushing techniques, can also manifest with recession defects on the facial surfaces of their teeth. Several studies reported the effect of the duration of tooth brushing, brushing force, frequency of changing the toothbrush, bristle hardness, and tooth brushing technique on GR. ${ }^{7,8,9}$ It was demonstrated that patients who used the horizontal tooth brushing technique had more GR than those who used the Bass or circular techniques, even in those who brushed only once per day with medium hardness bristles. ${ }^{10}$

There is also a risk of initiation or progression of GR during or after orthodontic treatment according to the direction of orthodontic movement. ${ }^{2}$ Other factors that may contribute to GR include frenal muscle pull, pre-existing alveolar bone defects such as dehiscences and/or fenestrations at the recession site, and iatrogenic factors related to restorative or periodontal procedures..$^{9,11,12}$

Tongue and perioral piercing known as body art - has been directly related to dental and gingival injuries on the lingual aspect of the lower anterior teeth and buccal GR may develop adjacent to a lip stud due to gingival trauma. ${ }^{13}$ Along with the subsequent esthetic challenge, GR may also contribute to functional problems such as tooth hypersensitivity, root caries, and noncarious cervical lesions such as abrasion, erosion, and cervical wear as a consequence of the exposure of the root surface to the oral environment. ${ }^{4}$

Many classifications have been proposed to facilitate diagnosing GR. The first classification was proposed by Ariaudo in 1966 and included three classes. Class I is a denuded root surface without periodontal pockets, treatment of which could result in total root coverage. Class II is a denuded root surface with shallow periodontal pockets on adjacent teeth; they show improvement with the laterally positioned flap but the root surface will be incompletely covered. Class III is a denuded root surface with a deep pocket coexisting on the same tooth or adjacent teeth where there will be minimal root surface coverage. Sullivan and Atkins introduced the use of the descriptive terms "narrow," "wide," "shallow," and "deep" to classify GR into four groups with a focus on mandibular incisor teeth, but no predictive value for treatment outcome was used. Mlinek et al. quantified GR into "shallow-narrow" clefts if they were $<3 \mathrm{~mm}$ in both dimensions, and "deep-wide"' defects if they were $>3 \mathrm{~mm}$ in both dimensions. ${ }^{14,15,16}$ In 1985, Miller classified GR into four classes, based on involvement of the mucogingival junction (MGJ), the level of interproximal bone, soft tissue loss, and tooth alignment. In class I, marginal tissue recession does not extend to the MGJ and there is no loss of interdental bone or soft tissue. In class II, marginal recession extends to or beyond the MGJ with no loss of interdental bone or soft tissue. Class III describes marginal tissue recession extending to or beyond the MGJ with loss of interdental bone or soft tissue extending apical to the CEJ but coronal to the apical extent of the marginal tissue recession. In class IV marginal tissue recession extends to or beyond the MGJ with loss of interdental bone or soft tissue extending to a level apical to the extent of the marginal tissue recession. ${ }^{17}$

Miller's classification is considered the most commonly used one among clinicians as it is considered to have a predictive value for the amount of root coverage following surgical procedures. ${ }^{18}$ However, it proved inadequate for several reasons; first of all, it does not take into consideration all cases of GR; for example, palatal recession is not mentioned in the classification. Another aspect is the difficulty in distinguishing between Miller class I and II recessions especially in the absence of an MGJ on the palatal side. Considering class III and IV, it is not always easy to determine the amount of hard and/or soft tissue loss interdentally to differentiate between the two 
classes. ${ }^{19}$ Furthermore, the prognostic anticipation of the amount of root coverage is too complex to draw theoretically without reliable data from randomized controlled trials (RCTs). The amount of root coverage achieved, cannot be solely predicted on the basis of the class of recession. For example, a class I GR might have a poor prognosis if anatomical and etiological factors are not controlled and if the operator's technical skills are questionable. ${ }^{18}$ Modifications for Miller's classification were suggested, where the profile of the gingiva, particularly gingival thickness, is taken into consideration as an important criterion for prognosis assessment (>0.8 $\mathrm{mm}$ improves the prognosis) ${ }^{20}$

In 1997, Smith introduced a classification described by a letter and two digits (e.g. F2-4). The letters F or L denote whether the GR is on the facial or lingual aspect of the tooth, and the two digits denote the horizontal and vertical components of a recession site, respectively. An asterisk $\left({ }^{*}\right)$ is added to the second digit when the vertical component extends to or beyond the MGJ. ${ }^{21}$ However, Smith included the horizontal and vertical components of radicular recession and disregarded the involvement of interdental tissues. ${ }^{18}$ Marini et al. in 2004 classified GR into mild, moderate, and advanced based on the amount of root surface exposure to the oral environment, where $\leq 3.0 \mathrm{~mm}$ of exposure is considered mild, $3.0-4.0 \mathrm{~mm}$ is moderate, and $>4.0 \mathrm{~mm}$ is advanced. ${ }^{22}$

In 2011, Rotundo et al. proposed a new classification based on the width of keratinized tissue, non-carious cervical lesions, and interproximal attachment loss. ${ }^{23}$ In the same year, Cairo et al. suggested a classification which they claimed to achieve a more standardized diagnosis by taking into consideration interdental clinical attachment loss. In recession type 1 (RT1) (GR without interproximal attachment loss), the interproximal CEJ is not clinically detectable both mesially and distally. In RT2 (GR with mild loss of interproximal attachment), the amount of interproximal attachment loss is less than or equal to the buccal attachment loss. In RT3 (GR with advanced loss of interproximal attachment), the amount of interproximal attachment loss is greater than the buccal attachment loss. In Cairo RT1, similar to Miller Class I and II, 100\% root coverage can be predicted; in Cairo RT2, similar to Miller class III, some randomized clinical trials have indicated a limit as to the amount of interdental clinical attachment loss within which $100 \%$ root coverage is predictable after applying different root coverage procedures; akin to Miller class IV, full root coverage is not achievable in Cairo RT3. ${ }^{24}$

In 2012, Chambrone et al. conducted a meta-analysis that pinpointed the effect of GR depth on the outcome of root coverage procedures, which indicated that increased GR depth decreases the possibility of complete root coverage. ${ }^{25}$ In 2013, Kumar and Masamatti introduced a new classification for facial surfaces of maxillary teeth as well as facial and lingual surfaces of mandibular teeth. In addition, it included a classification for interdental papilla recession. However, the outcome of different root coverage procedures depends on many factors, mainly the tooth position and topography of surrounding alveolar bone along with anatomical factors (including gingival biotype and the presence of fenestrations or dehiscences), the periodontal status, plaque index, severity of attachment loss, smoking, control of risk factors, occlusal load, and systemic makeup. ${ }^{18}$

Taking into consideration the various aspects of former classifications, a new diagnostic approach of the dentogingival unit was proposed in 2017 by Jepsen et al. in the "World Workshop on the Classification of Periodontal and PeriImplant Diseases and Conditions" to classify GR, associated mucogingival conditions, and cervical lesions with a treatment oriented vision using Cairo et al.'s classification of GR as a reliable basis (Table 1). ${ }^{26}$

Many epidemiological studies have been conducted on the prevalence of GR, which varied from $50 \%$ to $90 \%$ in different populations. However, the prevalence of GR and associated risk factors must be viewed taking into consideration the distinct profile of the studied population. $7,27,28,29$ There is a 
in Egypt, so the present study aimed to

Table 1. Classification of gingival biotype and GR

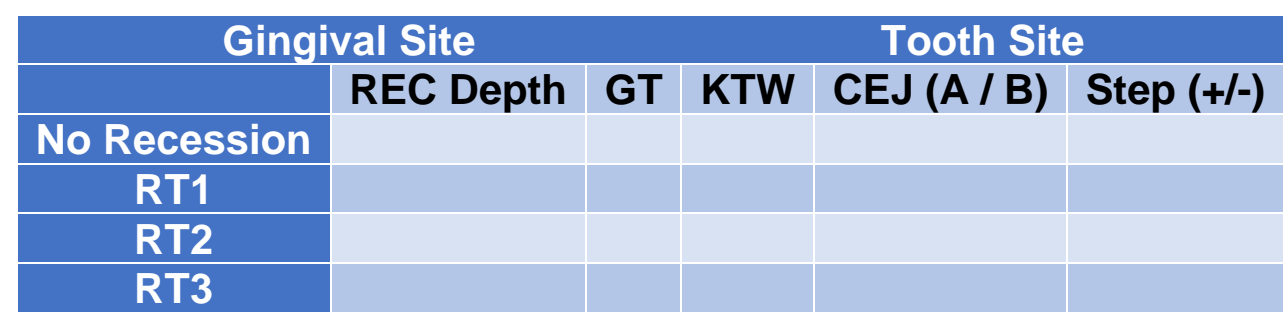

RT: recession type; REC Depth: recession depth; GT: gingival thickness; KTW: keratinized tissue width; CEJ: cemento-enamel junction (Class A: detectable CEJ; Class B: undetectable CEJ); Step: root surface concavity (Class + : presence of a cervical step $>0.5 \mathrm{~mm}$; Class -: absence of cervical step)

\section{Materials and Methods}

The present study was carried out at the Department of Periodontology at Cairo University's Faculty of Oral and Dental Medicine. Five hundred adults, both males and females, aged 18-60 years were included. In order to avoid an error in estimating the prevalence of GR and its possible associations, only subjects with a minimum of 20 remaining teeth were included. Third molars and remaining roots were excluded from the study. ${ }^{4}$

In this cross-sectional study, a full mouth clinical examination was performed in order to avoid a biased diagnosis of periodontal disease generated by partial periodontal recording protocols. The clinical examination was performed by the first author at 6 points using the University of Michigan "O" probe with Williams markings. Clinical attachment level (CAL) and GR measurements were rounded to the nearest millimeter. Gingival recession was defined as the distance from the cemento-enamel junction (CEJ) to the free gingival margin. All permanent fully erupted teeth were examined excluding the third molars. ${ }^{4,26}$

After evaluation of the overall periodontal condition, the facial surface of each tooth was examined for the presence of cervical abrasion in order to identify faulty and/or aggressive toothbrushing. The width of attached gingiva was measured and the site of attachment of the upper and lower frenula was identified in order to determine the presence of high frenal pull using tension and pull tests. ${ }^{30}$

For sample size calculation, the authors used the Epiifo ${ }^{\mathrm{TM}}$ software. The acceptable margin of error was set at $5 \%$. The expected frequency was $63.9 \%$, based on a prevalence study conducted on the Greek population. ${ }^{4}$ The expected total sample size was 434 , with a confidence level of $97 \%$. The authors agreed on a total of 500 subjects to be included in the present study. The Fisher exact test was used for statistical analysis and categorical data were analyzed using the Chi-square test via the IBMB Statistical Package for Social Sciences

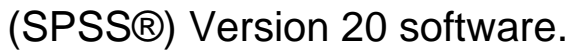

\section{Results}

A sample of 500 adult subjects was drawn from patients attending the Faculty of Oral and Dental Medicine Hospital at Cairo University, where 186 males and 314 females were examined. The overall prevalence of GR on all surfaces was $69.4 \%$ (Table 2). In the present study, the most common factors associated with GR were found to be dental plaque and periodontitis, whether the localized or generalized form, accounting for $90.8 \%$ of overall GR cases. The presence of a local predisposing factor accounted for $8.7 \%$ of all cases. Frenal pull was found to be the most prevalent local factor associated with GR with a prevalence of $54.8 \%$ compared to other local factors such as tooth malposition, which accounted for $25.8 \%$ of cases, or a lack of attached 
gingiva at a particular site, accounting for $6.5 \%$ of cases.

Table 2. Prevalence of GR

\begin{tabular}{c|c|c|c|}
\hline \multirow{2}{*}{ Gender } & Male & 186 & $37.2 \%$ \\
\cline { 2 - 4 } & Female & 314 & $62.8 \%$ \\
\hline \multirow{2}{*}{ GR } & No GR & 153 & $30.6 \%$ \\
\hline & GR & 347 & $69.4 \%$ \\
\hline
\end{tabular}

When all tooth sites for the whole mouth were considered, $38.9 \%$ of patients had localized GR with the mandibular incisors showing the highest prevalence, particularly the lingual surface (Table 3 ). Gender analysis showed a significant male predilection for GR, and a significant association of male GR with periodontitis which was found in $96.5 \%$ of cases. On the other hand, significantly more females suffered from localized GR compared to their male counterparts (Table 4).

Table 3. Risk factors for GR

\begin{tabular}{|c|c|c|c|}
\hline \multirow{3}{*}{ Risk for GR } & Periodontitis & N & $\%$ \\
\hline \multirow{3}{*}{ Distribution } & Local Factors & 30 & $90.8 \%$ \\
\hline & Chemotherapy/Radiotherapy & 1 & $8.7 \%$ \\
\hline \multirow{3}{*}{ Local Factors } & Toothbrushing & 1 & $0.3 \%$ \\
\hline & Localized & 137 & $38.9 \%$ \\
\hline & Generalized & 215 & $61.1 \%$ \\
\hline \multirow{2}{*}{ Systemic Disease } & Crowding & 2 & $6.5 \%$ \\
\hline & Malponal Pull & 17 & $54.8 \%$ \\
\hline & No Attached Gingiva & 8 & $25.8 \%$ \\
\hline & Orthodontic Treatment & 1 & $6.5 \%$ \\
\hline & No Diabetes Mellitus & 1 & $3.2 \%$ \\
\hline & Diabetes Mellitus & 11 & $97.2 \%$ \\
\hline
\end{tabular}

Table 4. Gender differences in GR

\begin{tabular}{|c|c|c|c|c|c|c|c|}
\hline & & \multicolumn{4}{|c|}{ Gender } & \multirow{3}{*}{ Test } & \multirow{3}{*}{$\mathbf{P}$} \\
\hline & & \multicolumn{2}{|c|}{ Male } & \multicolumn{2}{|c|}{ Female } & & \\
\hline & & $\mathrm{N}$ & $\%$ & $\mathrm{~N}$ & $\%$ & & \\
\hline \multirow{2}{*}{$\mathbf{G R}^{\mathbf{a}}$} & No GR & 42 & $22.6 \%$ & 111 & $35.4 \%$ & \multirow{2}{*}{8.969} & \multirow{2}{*}{$.003^{*}$} \\
\hline & GR & 144 & $77.4 \%$ & 203 & $64.6 \%$ & & \\
\hline \multirow{4}{*}{ Risk for $\mathbf{G R}^{\mathbf{b}}$} & Periodontitis & 139 & $96.5 \%$ & 175 & $86.6 \%$ & \multirow{4}{*}{13.637} & \multirow{4}{*}{$.001^{*}$} \\
\hline & Local Factors & 4 & $2.8 \%$ & 26 & $12.9 \%$ & & \\
\hline & Chemo/Radiotherapy & 1 & $0.7 \%$ & 0 & $0.0 \%$ & & \\
\hline & Toothbrushing & 0 & $0.0 \%$ & 1 & $0.5 \%$ & & \\
\hline \multirow{2}{*}{ Distribution ${ }^{a}$} & Localized & 38 & $25.9 \%$ & 99 & $48.3 \%$ & \multirow{2}{*}{18.138} & \multirow{2}{*}{$.000^{*}$} \\
\hline & Generalized & 109 & $74.1 \%$ & 106 & $51.7 \%$ & & \\
\hline \multirow{6}{*}{$\begin{array}{l}\text { Local } \\
\text { Factors }^{b}\end{array}$} & Crowding & 0 & $0.0 \%$ & 2 & $7.4 \%$ & \multirow{6}{*}{5.871} & \multirow{6}{*}{.337} \\
\hline & Frenal Pull & 1 & $25.0 \%$ & 16 & $59.3 \%$ & & \\
\hline & Malposed Tooth & 2 & $50.0 \%$ & 6 & $22.2 \%$ & & \\
\hline & No Attached Gingiva & 1 & $25.0 \%$ & 1 & $3.7 \%$ & & \\
\hline & $\begin{array}{l}\text { Orthodontic } \\
\text { Treatment }\end{array}$ & 0 & $0.0 \%$ & 1 & $3.7 \%$ & & \\
\hline & Unknown & 0 & $0.0 \%$ & 1 & $3.7 \%$ & & \\
\hline Systemic & No Diabetes Mellitus & 182 & $97.8 \%$ & 307 & $97.8 \%$ & \multirow{2}{*}{--- } & \multirow{2}{*}{1.000} \\
\hline Disease $^{b}$ & Diabetes Mellitus & 4 & $2.2 \%$ & 7 & $2.2 \%$ & & \\
\hline
\end{tabular}

${ }^{\mathrm{a} C h i-s q u a r e ~ t e s t ; ~}{ }^{\mathrm{b}}$ Fisher exact test; ${ }^{*}$ significant at $\mathrm{P}<0.05$

\section{Discussion}

Epidemiological studies offer unique information that is hard to obtain through any other study design. They shed light on the distribution of disease amongst a given population, and the possible relationship between different etiologic factors or 
predisposing factors underlying disease progression. Although it is not a disease entity, GR causes problems of high concern to dental patients, such as poor esthetics and tooth hypersensitivity. ${ }^{31}$

In the present study, 500 patients were included where females represented $62.8 \%$ of the sample while males accounted for $37.2 \%$. This may be attributed to a higher motivation shown by females to maintain a healthy dentition. The results of the present study also demonstrated that GR is a common condition with a total prevalence of $69.4 \%$. This correlates with Muller et al.'s results, who found that $50 \%$ of young adults in Germany (19-30 years) suffered from GR in at least one site. Thus, GR is a common finding in any population irrespective of age and ethnicity. ${ }^{32}$

The present study demonstrated a male predilection of $77.4 \%$ for GR and this result is in accordance with Dodwad who studied the prevalence of GR in India, and found that $67 \%$ of patients with GR were males and $33 \%$ were females. ${ }^{33}$ Several other studies also showed a higher prevalence of GR in males compared to females. ${ }^{7,29}$ The generally higher prevalence of GR in males can be attributed to a lower concern with oral hygiene and esthetics as compared to females. Contrarily, other studies showed a female predilection for GR. ${ }^{4,34}$

Within the given population, periodontitis was deemed to be the main contributing factor for GR as it accounts for $90.8 \%$ of total recession areas $(86.6 \%$ and $96.5 \%$ in males and females respectively). This may be due to the low socioeconomic status of the sample population, which was drawn from a public university hospital and was comprised of patients who have limited resources for proper oral hygiene practices. These results are comparable with Chrysanthakopoulos who reported a positive correlation between plaque and calculus accumulation, and GR (both localized and generalized forms). ${ }^{10}$ The role of supragingival calculus as an important factor that is usually associated with GR may be explained by the fact that dental plaque is kept in close proximity with tissues creating areas where plaque removal is out of reach. ${ }^{7}$ Likewise, Manchala et al. who studied the epidemiology of GR in the Indian population, found that more than $80 \%$ of participants above 35 years of age had $>40 \%$ of their teeth covered with calculus which was strongly associated with GR. ${ }^{28}$ Mythri et al. reported that the recession group had a clinical attachment loss $>3 \mathrm{~mm}$ in $99.7 \%$ of all cases. ${ }^{30}$

The most commonly affected site was the lower anterior teeth for localized GR cases in the present study. These results are in line with Mythri et al., who observed that GR was more commonly present in the mandibular arch $(66 \%)$ compared to the maxillary arch (34\%), and recession around lower incisors accounted for $43 \%$ of the total GR in the oral cavity. ${ }^{30}$ Dodwad also reported in his prevalence study that about $87 \%$ of patients showed GR in the lower anterior area. ${ }^{33}$ This could be ascribed to several factors; firstly, GR is found in areas where alveolar bone is thin or almost absent; second is that the lingual surfaces of lower anterior teeth represent a major retentive area for plaque and calculus in the oral cavity; and third, a high frenal pull may act as a local factor on the labial surface of lower central incisors. On the other hand, the study conducted by Chrysanthakopoulos in 2011 demonstrated that $35.3 \%$ of GR was around the upper first and second molars, and $28.7 \%$ of GR was around the lower first and second molars. ${ }^{10}$

An interesting finding of this study is that frenal pull was found to have a profound negative association with GR when it comes to different local factors interplaying in the etiology of GR ( $1.9 \%$ of total recession causes and $54.8 \%$ of local factors). This may be attributed to a shallow vestibule with/without several small frenula, a narrow zone of keratinized tissue and thin interdental bone which all magnify the frenal pull effect upon the offended teeth. These results are more pronounced than those reported by Mythri et al. in 2015, who found that frenal pull accounted for only $0.4 \%$ of the factors predisposing to GR. ${ }^{30}$ Contrarily, in 2009, Lafzi et al. reported an insignificant association between frenal attachment and GR. ${ }^{11}$ 
Despite the limitations of the crosssectional study design, as it does not allow inference about causality, this surveillance is important for describing the burden of GR in the adult Egyptian population, identifying persons at high risk and helping develop awareness programs and strategies to control the condition which can positively impact the patients' quality of life. Such strategies may include modifying oral hygiene behavior, using desensitizing agents, periodontal therapy, and root coverage procedures. ${ }^{27,1}$

Gingival recession is associated with different clinical problems that can present a challenge when deciding whether or not to use surgical intervention. A key question to answer is: what happens if GR is left untreated? In this case, the main goal of therapy should be to address each patient's needs, and treatment options should be presented to them. ${ }^{27} \mathrm{~A}$ survey conducted among dental clinicians showed that esthetics accounted for $90.7 \%$ of the reasons for root coverage procedures. ${ }^{35}$ Therefore, perception of GR and the patients' needs should be carefully assessed before proceeding to treatment using the Smile Esthetic Index (SEI), where ten variables are used as determinants for the esthetics of a smile: smile line and facial midline, tooth alignment, tooth deformity, tooth dyschromia, gingival dyschromia, GR, gingival excess, gingival scars, and diastema/missing papillae. ${ }^{2}$

Dentinal hypersensitivity is also a common complaint resulting from exposure of the root surface to the oral environment. In a study on 404 patients, 795 teeth were clinically diagnosed with dentinal hypersensitivity with an overall prevalence of $20.6 \%$, in which the presence of GR was highly significant $(56.8 \%)$ and represented the most prominent factor. ${ }^{36}$ The pain is short and sharp, happens immediately after stimulation of exposed dentin, and resolves on removal of the stimulus. Due to increased tooth life expectancy with people retaining more vital or minimally restored teeth, dentinal hypersensitivity tends to become more frequent and can negatively impact quality of life, particularly in elderly patients. Treatment strategies include root surface treatment or root coverage procedures. However, there is insufficient data on the predictability of the effectiveness of surgical root coverage procedures on dentinal hypersensitivity. ${ }^{2}$

To summarize, GR is a highly prevalent condition among Egyptians, and there is insufficient dental health awareness among the Egyptian population. Therefore, future multicenter surveillance studies are needed to obtain a representative sample of the whole Egyptian population in an effort to develop effective preventive strategies and possibly a new classification that addresses treatment of GR.

\section{References}

1. Eke PI, Thornton-Evans G, Dye B, Genco R. Advances in surveillance of periodontitis: the Centers for Disease Control and Prevention periodontal disease surveillance project. $J$ Periodontol. 2012 Nov; 83(11):133742.

https://doi.org/10.1902/jop.2012.110 676

2. Cortellini P, Bissada NF. Mucogingival conditions in the natural dentition: Narrative review, case definitions, and diagnostic considerations. J Periodontol. 2018 Jun; 89 Suppl 1:S204-S213. https://doi.org/10.1002/JPER.160671

3. Zucchelli G, Mounssif I. Periodontal plastic surgery. Periodontol 2000. 2015 Apr; 68(1):333-68. https://doi.org/10.1111/prd.12059

4. Chrysanthakopoulos, NA. Gingival recession: prevalence and risk indicators among young greek adults. J Clin Exp Dent. 2014 Jul; 6(3):e2439. https://doi.org/10.4317/jced.51354

5. Serino G, Wennström JL, Lindhe J,

Eneroth $L$. The prevalence and distribution of gingival recession in subjects with a high standard of oral hygiene. J Clin Periodontol. 1994 Jan; 21(1):57-63. https://doi.org/10.1111/j.1600051X.1994.tb00278.x

6. Yoneyama $\mathrm{T}$, Okamoto $\mathrm{H}$, Lindhe $\mathrm{J}$, Socransky SS, Haffajee AD. Probing 
depth, attachment loss and gingival recession. Findings from a clinical examination in Ushiku, Japan. $J$ Clin Periodontol. 1988 Oct; 15(9):581-91. https://doi.org/10.1111/j.1600051x.1988.tb02133.x

7. Toker H, Ozdemir H. Gingival recession: epidemiology and risk indicators in a university dental hospital in Turkey. Int J Dent Hyg. 2009 May; 7(2):115-20. https://doi.org/10.1111/j.16015037.2008.00348.x

8. Kapferer I, Benesch T, Gregoric N, Ulm C, Hienz SA. Lip piercing: prevalence of associated gingival recession and contributing factors. A cross-sectional study. J Periodontal Res. 2007 Apr; 42(2):177-83. https://doi.org/10.1111/j.16000765.2006.00931.x

9. Kassab MM, Cohen RE. The etiology and prevalence of gingival recession. J Am Dent Assoc. 2003 Feb; 134(2):220-5.

https://doi.org/10.14219/jada.archive. 2003.0137

10. Chrysanthakopoulos, NA. Aetiology and Severity of Gingival Recession in an Adult Population Sample in Greece. Dental Res J. 2011 Spring; 8(2):64-70.

11. Lafzi A, Abolfazli N, Eskandari A. Assessment of the Etiologic Factors of Gingival Recession in a Group of Patients in Northwest Iran. J Dent Res Dent Clin Dent Prospects. 2009 Sep; 3(3):90-93. https://doi.org/10.5681/joddd.2009.0 23

12. Chan HL, Chun YH, MacEachern M, Oates TW. Does Gingival Recession Recession Require Surgical Treatment? Dent Clin North Am. 2015 Oct; 59(4):981-96. https://doi.org/10.1016/j.cden.2015.0 6.010

13. Campbell A, Moore A, Williams E, Stephens J, Tatakis, DN. Tongue piercing: impact of time and barbell stem length on lingual gingival recession and tooth chipping. $J$ Periodontol. 2002 Mar; 73(3):289-97. https://doi.org/10.1902/jop.2002.73.3 .289

14. Ariaudo AA. Problems in treating a denuded labial root surface of a lower incisor. J Periodontol. 1966 Jul-Aug; 37(4):274-8.

https://doi.org/10.1902/jop.1966.37.4 .274

15. Sullivan HC, Atkins JH. Free autogenous gingival grafts. 3 . Utilization of grafts in the treatment of gingival recession. Periodontics. 1968 Aug; 6(4):152-60.

16. Mlinek $A$, Smukler $H$, Buchner $A$. The use of free gingival grafts for the coverage of denuded roots. $J$ Periodontol. 1973 Apr; 44(4):248-54. https://doi.org/10.1902/jop.1973.44.4 .248

17. Miller PD Jr. A classification of marginal tissue recession. Int $J$ Periodontics Restorative Dent. 1985; 5(2):8-13.

18. Thakur RK. Classification of Gingival Recession: A New Approach. Int J Dent Health Sci. 2015; 2(6):16121623.

19. Pini-Prato G. The Miller classification of gingival recession: limits and drawbacks. J Clin Periodontol. 2011 Mar. 38(3):243-5. https://doi.org/10.1111/j.1600051X.2010.01655.X

20. Mahajan A. Mahajan's Modification of the Miller's Classification for Gingival Recession. Dent Hypotheses. 2010 Aug; 1(2):45-50. https://doi.org/10.5436/j.dehy.2010.1 .0009

21. Smith RG. Gingival recession. Reappraisal of an enigmatic condition and a new index for monitoring. $J$ Clin Periodontol. 1997 Mar; 24(3):201-5. https://doi.org/10.1111/j.1600051x.1997.tb00492.x

22. Marini MG, Greghi SL, Passanezi E, Sant'ana AC. Gingival recession: prevalence, extension and severity in adults. J Appl Oral Sci. 2004 Sep; 12(3):250-5.

https://doi.org/10.1590/s167877572004000300017

23. Rotundo R, Mori M, Bonaccini $D$, Baldi C. Intra- and inter-rater 
agreement of a new classification system of gingival recession defects. Eur J Oral Implantol. 2011 Summer; 4(2):127-33.

24. Cairo F, Nieri M, Cincinelli S, Mervelt $J$, Pagliaro U. The interproximal clinical attachment level to classify gingival recessions and predict root coverage outcomes: an explorative and reliability study. $J$ Clin Periodontol. $2011 \mathrm{Jul}$; 38(7):661-6. https://doi.org/ 10.1111/j.1600051X.2011.01732.x

25. Chambrone L, Pannuti CM, Tu YK, Chambrone LA. Evidence based periodontal plastic surgery. II. An individual data meta-analysis for evaluating factors in achieving complete root coverage. $J$ Periodontol. 2012 Apr; 83(4):477-90. https://doi.org/10.1902/jop.2011.110 382

26. Jepsen S, Caton JG, Albandar JM, et al. Periodontal manifestations of systemic diseases and developmental and acquired conditions: Consensus report of workgroup 3 of the 2017 World Workshop on the Classification of Periodontal and Peri-Implant Diseases and Conditions. $J$ Periodontol. 2018; 89(Suppl 1): S237-S248.

https://doi.org/10.1002/JPER.170733

27. Wagner TP, Costa RSA, Rios FS, et al. Gingival recession and oral healthrelated quality of life: a populationbased cross-sectional study in Brazil. Community Dent Oral Epidemiol. 2016 August; 44(4):390-399. https://doi.org/10.1111/cdoe.12226

28. Manchala SR, Vandana $\mathrm{KL}$, Mandalapu NB, Mannem S, Dwarakanath CD. Epidemiology of gingival recession and risk indicators in dental hospital population of Bhimavaram. J Int Soc Prev Community Dent. 2012 Jul; 2(2):6974. $\quad$ https://doi.org/10.4103/22310762.109374

29. Albandar JM, Kingman A. Gingival recession, gingival bleeding, and dental calculus in adults 30 years of age and older in the United States, 1988-1994. J Periodontol. 1999 Jan; 70(1):30-43.

https://doi.org//10.1902/jop.1999.70. 1.30

30. Mythri S, Arunkumar SM, Hegde S, Rajesh SK, Munaz M, Ashwin D. Etiology and occurrence of gingival recession - An epidemiological study. $J$ Indian Soc Periodontol. 2015 NovDec; 19(6):671-5. https://doi.org/10.4103/0972124X.156881

31. Tugnait A, Clerehugh V. Gingival recession-its significance and management. J Dent. 2001 Aug; 29(6):381-94.

https://doi.org/10.1016/s03005712(01)00035-5

32. Müller HP, Stadermann S, Heinecke A. Gingival recession in smokers and non-smokers with minimal periodontal disease. $J$ Clin Periodontol. 2002 Feb; 29(2):129-36. https://doi.org/10.1034/j.1600051x.2002.290207.x

33. Dodwad V. Aetiology and severity of gingival recession among young individuals in Belgaum district in India. Annal Dent Univ Malaya. 2001; (8) 1-6.

34. Kozłowska M, Wawrzyn-Sobczak K, Karczewski JK, Stokowska W. The oral cavity hygiene as the basic element of the gingival recession prophylaxis. Rocz Akad Med Bialymst. 2005; 50 Suppl 1:234-7.

35. Zaher CA, Hachem J, Puhan MA, Mombelli A. Interest in periodontology and preferences for treatment of localized gingival recessions. J Clin Periodontol. 2005 Apr; 32(4):375-82. https://doi.org/10.1111/j.1600051x.2005.00690.x

36. Haneet RK, Vandana LK. Prevalence of dentinal hypersensitivity and study of associated factors: a crosssectional study based on the general dental population of Davangere, Karnataka, India. Int Dent J. 2016 Feb; 66(1):49-57. https://doi.org/10.1111/idj.12206 
Conflicts of interest: The authors declared no conflicts of interest related to this work.

\section{Corresponding author:}

Dr. Marwa Hegab

Assistant Professor, Department of Periodontology

Faculty of Oral and Dental Medicine

Cairo University
11 El-Saraya St.

Manial

Cairo,Egypt

E-mail:marwa.hegab@dentistry.cu.edu.eg

This is an open access article distributed under the Creative Commons AttributionNoncommercial-NoDerivatives 4.0 International (CC BY-NC-ND 4.0) License. 